\title{
Lessons From Developing a Community-Based Counseling Training Center*
}

\author{
Marta Garrett, H. Ty Leonard, Jason Martin, Connie Eary, William Benner \\ University of Mary Hardin-Baylor, Belton, USA
}

\begin{abstract}
Master's level counselor education programs typically require hands-on practicum and internship courses to enhance the development of students' counseling skills. Many programs use on-campus training facilities to observe student-counselors with real clients because this allows faculty to provide close supervision while they monitor the skill development of their counseling students. Creating a facility to enable these kinds of training opportunities requires considerable business and management knowledge and skills beyond the expertise of most counselor educators. Additionally, this type of facility demands a substantialinitial and on-going budget allocation for space, personnel, equipment, and training. This case study describes the evolutionary process of CLC (the Community Life Counseling Center) — the counseling training facility of a small, private religiously-affiliated university in Central Texas. This case study discusses the conception of the CLC more than a decade ago to fully-operational status today. Over the last nine years, this facility has evolved and developed and is now a well-known and well-respected counseling clinic in the local community having been used to provide more than 11,000 clients sessions.
\end{abstract}

Keywords: community clinic, counselor education, training center

\section{Introduction}

This article discusses the need for on-campus counselor training facilities and the evolution of one such training facility, the CLC, which was designed to support the training needs of a master's level counseling program at a small, private, Christian university in Central Texas. The CLC was specifically designed to meet the training needs of UMHB (the Graduate Counseling Program at University of Mary Hardin-Baylor) which currently offers two 60-credit master's programs in counseling - one in Clinical Mental Health Counseling (accredited by CACREP (the Council for Accreditation of Counseling and Related Educational Programs) since 2004 (originally accredited as a Community Counseling Program)), and one in Marriage, Family, and Child Counseling (currently seeking CACREP accreditation). The CLC first opened on the edge of the UMHB campus in Belton, Texas, in August, 2005. Over the last nine and a half years, the CLC has provided counselor training opportunities for more 200 graduate counseling students and has made more than 11,000 free or nearly

\footnotetext{
${ }^{*}$ This paper was presented at the Hawaii International Conference on Education (HICE), Honolulu, H.I., January 5, 2015. Marta Garrett, Associate Professor of Counseling, Director, Graduate Counseling Program, University of Mary Hardin-Baylor. H. Ty Leonard, Associate Professor, the Community Life Counseling Center, University of Mary Hardin-Baylor. Jason Martin, Assistant Professor, Director of the Community Life Counseling Center, University of Mary Hardin-Baylor. Connie Eary, Clinical Adjunct Supervisor, the Community Life Counseling Center, University of Mary Hardin-Baylor. William Benner, Clinical Adjunct Supervisor, University of Mary Hardin-Baylor.
} 
free counseling sessions available to clients in the community who might not otherwise have been able to afford mental health services.

Much of the history and details of the early evolution of the CLC was gathered in a series of interviews and discussion during the Fall 2013 and Spring 2014, with Dr. Raylene Statz, now retired, who served as the former Graduate Counseling Department Program Chair for more than a decade, and Dr. H. Ty Leonard, Associate Professor, and initial Director of the Community Life Center (who served in this role for eight years). More recent information regarding changes and future directions for the CLC was gathered from Dr. Jason Martin, Assistant Professor, who serves as the current Director of the CLC (since August, 2013).

\section{Background}

The master's level degree is generally viewed as the practitioner's degree in the mental health field providing the vast majority of independently licensed mental health practitioners in the country (for example, there are approximately 26,000 independently-licensed master's level practitioners in Texas alone, and roughly 375,000 in the United States (American Counseling Association, 2011). Training these master's level practitioners requires more than classroom instruction. Within the counseling profession, there is an expectation that graduates are capable of working with a variety of clients at the time they graduate (Engels, Barrio Minton, Ray, \& Associates, 2010; also see counseling position descriptions posted on various job search websites). This level of ability requires significant hands-on training and skill development while in graduate school, under the close supervision of faculty. Typically, this advanced training is addressed through a series of two to four semesters of practicum or internship at the end of graduate study where students are provided with the opportunity to work with increasingly demanding clinical presenting issues under the supervision of a licensed faculty member (e.g., Graduate Counseling Program Requirements, 2014; Texas State Board of Professional Counselors, 2014).

In addition to the stated expectations regarding competencies and performance for professional counseling students and graduates (e.g., Engels et al., 2010), this need for hands-on experience and training in counselor education is further emphasized by the accepted standards of ethical practice in the counseling profession (ACA, 2014; NBCC (National Board of Certified Counselors), 2012). The primary accrediting body for the counseling profession (CACREP) mandates professional training opportunities be made available to counseling students within accredited counselor education programs (CACREP, 2009). While this accrediting body does not specifically require training programs maintain or operate an on-campus clinic for training purposes, the accreditation standards clearly address the need for training under close faculty supervision (for example, the opportunity to view taped counseling sessions and/or provide live supervision for counseling students (CACREP, 2009)). When a counselor education program relies on an off-campus site for training opportunities, they can face issues with inconsistency or lack of adequate supervision. Thus as counselor education programs grow, they often prefer to manage their own training environments so that they can ensure students are getting the widest variety of clinical experiences under appropriate supervision.

Institutions generally follow one of two models of operating a counselor training facility on campus: a university counseling center that serves the counseling needs of the undergraduate student body; or an outreach-based counseling center that serves the counseling needs of members of the larger community and not the university student body (Henderson, 2010; Mobley \& Myers, 2010). Historically, programs that train master's level practitioners primarily have chosen to offer services to community residents to avoid potential 
conflicts of interest and dual relationships with undergraduate students on campus (Mobley \& Myers, 2010).

As accreditation of counseling training programs has become increasingly necessary for competitive job placement of graduates (Department of Defense, 2014), more training programs are seeking accreditation than ever before (CACREP, 2013). Currently there are 29 master's level counseling programs accredited by CACREP in Texas (CACREP, n.d.) and this number will likely to continue to grow in coming years. One of the larger obstacles for programs who wish to pursue national accreditation is the need to design, staff, manage, and fund a facility to adequately train their counseling students. This is particularly an issue for smaller, private, or religious institutions who are generally not able to rely on grants or funding from the state or federal government.

\section{Community and Cultural Influences on the CLC}

A deep understanding of local and institutional culture is paramount to creating a thriving counselor training facility. The history and culture of the Belton community and UMHB as an institution had a significant influence on the development of the Graduate Counseling Program and the affiliated counselor training facility, the CLC. Belton, Texas is approximately one hour north of Austin and one hour south of Waco. Fort Hood, the nation's largest military installation, lies directly to the west of Belton and has significant influence on the local area both in culture and in job opportunities. Belton is a small but rapidly expanding bedroom community in Central Texas. Over the last decade, Belton has grown from a few thousand residents to now just under 20,000 people. In the area surrounding Belton (30-minute drive each direction), there are approximately 250,000 people (City-data.com, 2014).

UMHB originated as a "sister college" to Baylor University in 1845 and remained a women's institution until 1974 (Our history, n.d.). UMHB (like the larger, more well-known, Baylor University) is affiliated with the Baptist General Convention of Texas. While these two institutions share similar historical experiences and structures, UMHB is perhaps considered more conservative than Baylor (as Baylor University went co-educational much earlier in its history). Today, UMHB has approximately 3,700 students - predominantly undergraduate students.

UMHB's Graduate Counseling Program first started as an extension of the undergraduate psychology department. As graduate level training became the norm for community-based counselors, the graduate program separated from the undergraduate department and began to focus more on counselor education. When the graduate counseling and psychology program was formed the faculty retained only graduate level teaching responsibilities - making it the first and only stand-alone graduate educational program on the UMHB campus. At that time, the Department primarily offered graduate level programs that led to LPC (the licensed professional counselor) credential and to certification in school counseling (additionally, the Department retained a non-licensure track that had started as a preparatory track for students who wished to pursue doctoral education). As LPC (the Licensed Professional Counselor) credential became the license of choice for master's level practitioners in Texas, the decision was made to emphasize counselor education programs rather than psychology programs. Today, the Clinical Mental Health Counseling track (preparing graduates to apply for the LPC) remains the strongest and largest of the programs offered in the Graduate Counseling Program (accounting for more than $75 \%$ of the Department's enrolled students).

When the Department decided to pursue national accreditation with CACREP, the remaining tracks that led to psychology credentialing were dropped and the faculty began to pursue a training facility to address the 
specific skill-development needs of counselors. Over time, several additional changes were made in the focus of the degrees offered by the Department to meet the changing needs of the local economy and job market. The Department added a second clinical focus on marriage and family counseling (initially this was offered with a Christian emphasis to complement the over-arching mission of the institution). Later, the Graduate Counseling Program dropped the word "psychology" from its title in an effort to better emphasize its connection to the counselor education field. Still later, a second marriage and family track (with additional coursework in counseling children) was added in order to pursue national accreditation in the marriage and family field. And, most recently, the Academic Specialization track (that does not lead to clinical licensure) was renamed to clarify its purpose as a non-clinical professional studies program (see Figure 1 for additional detail).

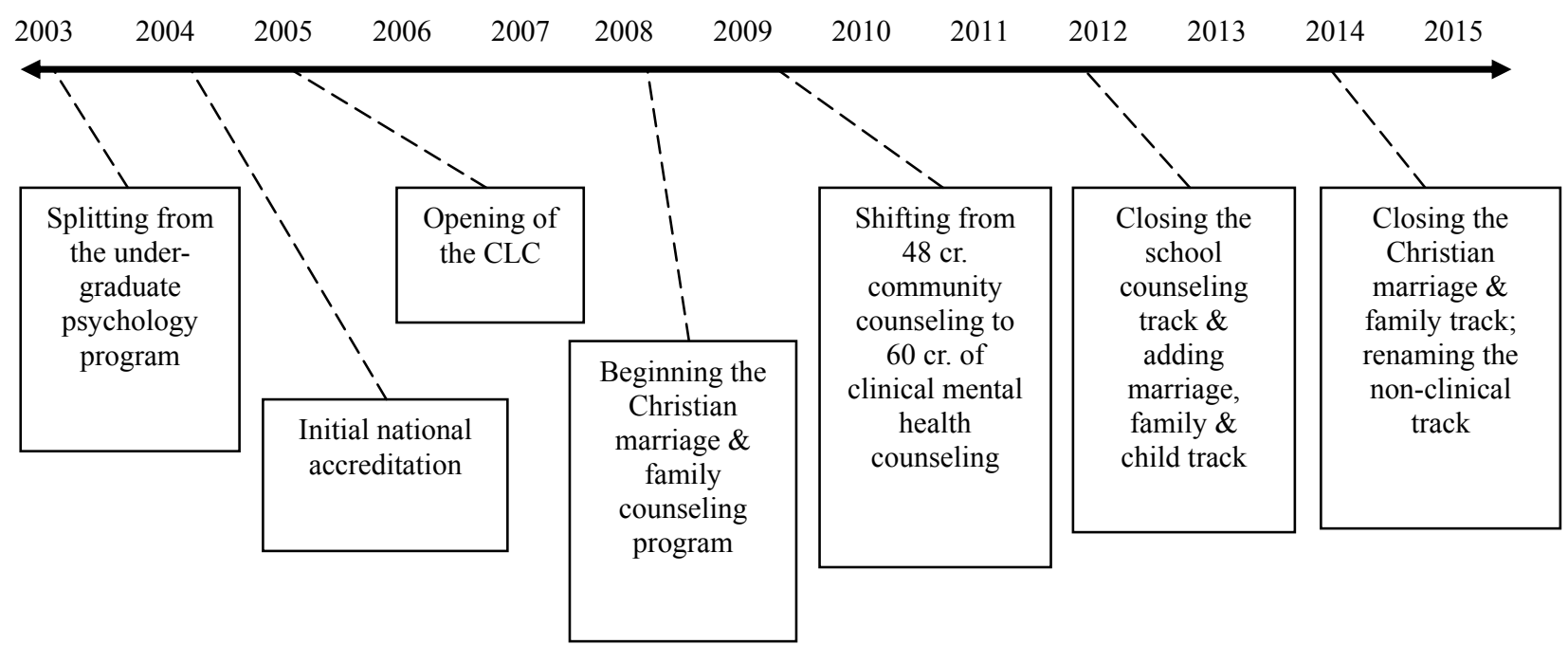

Figure 1. Time line of curricular changes in the Graduate Counseling Program.

\section{Laying the Groundwork for the CLC}

The decision to move forward with plans to open the CLC required significant preparatory work and planning. The Graduate Counseling Department prepared a lengthy proposal to demonstrate the need for the training facility to administrators. This proposal required describing the rationale for the training facility in detail - describing the need for the facility from both the counselor education standpoint as well as the potential benefit of adding an additional source for mental health care needs in the community. Budgeting issues were considered to include the added demand on faculty, space, and facilities. Legal advice was sought to determine how to best minimize any possible risks to the institution. Support was sought from faculty, administrators, and the institution's Board of Trustees. Additionally, support was solicited from local churches and mental health providers to ensure future referrals. This pre-planning phase of the development of the CLC occurred over approximately a two-year period of time.

Once approvals had been granted, an appropriate site was selected on the edge of campus to best meet the needs of the potential clients (transportation, easy to access from off campus, etc.). An older residence on the edge of campus was selected because of its location, size, price, and the desire to have a "homey" environment for the CLC (as opposed to a more sterile classroom-like building). Renovations to the building were required to make the building more suitable for client sessions. During the renovations and before opening the facility, all the client-based paperwork and processes were prearranged to minimize any potential surprises and risk. An 
advertising campaign was launched to announce to the community the purpose of the CLC and to bring in new clients. Finally, an open house was held and the CLC was officially open for business in August, 2005.

The Community Life Counseling Center has been in operation three to four week days each week since August, 2005. CLC operating hours have been adjusted to meet demands based on the number of students enrolled in practicum and/or internship each semester. Initially, the CLC was open even during the semester breaks and over the Christmas holiday and Spring break; however, more recently with a better understanding of client needs and other available resources in the area the CLC now has regularly scheduled closures for holidays and between semesters.

\section{Budgeting Issues}

Considerable effort was made to estimate the expenses of opening and operating a community-based mental health center to train counseling students. However, as might be anticipated, this is almost an impossible task. With constantly changing dynamics such as variable student enrollments, changes in accrediting standards, changes in licensing requirements, developing technology in the field, and fluctuations of clients, the unknown factors clearly outweigh the known factors in managing this type of a training clinic. Despite researching and querying similar clinics and training programs about the potential costs involved, much of the necessary information regarding budgeting and managing this type of clinic came only with experience.

At the time the Community Life Counseling Center was opened, monies were budgeted for procuring a space (about 1,800 square feet) and renovating the space to include moving walls, upgrading wiring, and adding interior doors for privacy and security (see Appendix for pictures and floor plans). An initial outlay for videotaping equipment was budgeted at approximately $\$ 5,000$. No additional faculty or staff lines were initially pursued. The remainder of the needed monies and materials was acquired through donations (to include furniture and other equipment such as toys for the play room). In recent years, significant additional funding has been added to the CLC operating budget for upgrading safety features and technology (both described in greater detail below).

The CLC was designed as a training facility and was never intended to be profitable. The administration of the university considers the services provided by the CLC as one of many ways the institution gives back to the larger community (which is closely tied to the institutional mission and philosophy). The CLC does not accept any form of insurance which simplifies many of the paperwork and money processes involved. It operates as a cash-and-carry business utilizing a sliding scale for services (from free to $\$ 20$ per session). Student counselors come to a fee agreement during the intake process based on the client's ability to pay. If a client is unable to pay for services, the fees may be waived entirely, but clients are encouraged to pay something for their counseling (even if it is a nominal fee) because negotiating fees in counseling and paying for these services help encourage client commitment to the therapeutic process, help clients value the counseling services they receive, and promote professional boundaries (e.g., Gutheil \& Gabbard, 1993). All monies that are generated from CLC services go back to the general operating fund of the institution.

\section{Staffing}

As described above, when the CLC first opened in 2005, there was no dedicated faculty line or course reduction provided for the director. This was a sacrifice that was needed to gain the support of the administration (R. Statz, personal communication, October, 10, 2013). The position of director was given to a tenure-track junior faculty member who retained all regular faculty duties (to include a full-time graduate 
teaching load, research, office hours, university committee duties, etc.). The Director was expected to be on-site at the CLC at any time that students were seeing clients. In the event that class or other commitments made this impossible, other faculty would "sub" for the Director to provide required on-site supervision coverage. Unfortunately, in the early years of the CLC's operation, there were no added clinical adjunct positions funded or office/support staff positions available for the CLC.

For the first several years of operation, the CLC was essentially manned by a single faculty member-requiring an average of 60 or more hours a week. As the graduate counseling program grew, so did the demands on the CLC director. This burden quickly became unmanageable and the CLC director was able to successfully lobby for, and acquire, the first one and then a second part-time clinical faculty. These two part-time clinical faculty were hired as adjuncts initially being paid the equivalent of teaching one graduate level counseling course for approximately 20 hours of supervision work at the CLC each week during the semester.

In the early years, with no administrative support staff available, counseling students enrolled in practicum or internship were required to be available for administrative duties at the CLC (e.g., answering client inquiries, booking appointments, etc.). After the CLC had been open a couple of years, the Director was able to successfully lobby for and acquire student worker assistance (graduate level student employees paid minimum wage who worked as administrative help at the CLC). By the seventh year of operation, the CLC had two student workers (each working approximately 12 hours a week). This assistance allowed for a smoother client-referral process and provided someone to greet new clients so that the clinical staff were not interrupted from their primary role of providing live supervision for counseling sessions.

\section{Continuing Evolution of the CLC}

Furnishings. Furnishings for this type of facility can be a costly endeavor to balance client comfort needs as well as durability. Over time, most of the donated furnishings in the CLC have been replaced with new and more generically appealing items (see Appendix for more detail). In this process, the overall decor of the CLC was updated to appeal to a broader group of potential clients. Consistency in furnishing between rooms was desired for both client comfort (should clients not be seen in the same room each session), and also for flexibility. For example, the group room chairs were replaced with roller chairs to allow more flexibility in how and where they can be used (they can be added to other counseling rooms for couples or larger family sessions or to seat an additional counseling student if needed in co-therapy).

In an effort to be able to better serve the growing number of child clients that are seen at the CLC, the play therapy room is currently being redesigned and moved to a less-central portion of the CLC for noise abatement. Old, worn out, or infrequently used play items have been removed, upgraded, and re-stocked. A substantial financial investment has been budgeted for this endeavor over the next three fiscal years. The sandtray room is also in the process of being converted to a more child-friendly space (currently it is used only for adolescents and adults due to safety issues with the shelving and the sandtray stand).

Due to the age of the CLC facility and the shapes of some of the counseling rooms, sound issues (e.g., echoes from the nine-foot ceilings, difficulty picking up soft voices on the microphones, etc.) continue to be a challenge. This has required multiple installations and adjustments of the recording equipment which can be costly; the installation of shag area rugs and sound panels in most of the rooms to absorb sound - also an added unplanned expense and the addition of white noise machines. 
Staffing. Within a few years of opening the CLC, it became apparent that it was an unfair burden to place all the responsibility for managing the clinic on one faculty member. Attempts were made to divvy up the responsibilities of the Director position, but these were unsuccessful as it was a challenge to partition and delegate these kinds of duties while maintaining stability of policies and practices. To ensure students received consistent and adequate supervision and that client safety was not compromised, the Director essentially performed two full-time positions until the administration came to understand the need for a separate and new faculty line for a clinic director. Once budgeting for a new clinic director was approved, it took nearly a year to advertise and hire this position.

Currently, the CLC Director's position is a nine-month, tenure-track regular faculty position (it is not designated as clinical faculty). The CLC Director position requires a minimum of 30 hours a week at the CLC and comes with a significantly reduced teaching load (the CLC Director teaches only one practicum or internship course each fall and spring). Because the CLC is open year-round, the CLC Director is paid by a separate contract for duties during the summer months. The CLC Director also has the ability to adjunct coverage hours at the CLC with the two part-time clinical faculty as described above (however, these clinical adjuncts now work 12-15 hours a week (versus the earlier 20 hours) for the equivalent pay of teaching one graduate level course). Thus, during the busier semester when practicum is being taught (during practicum, students gain all of their experience hours at the CLC and practicum students typically require more supervision than more advanced internship students), the CLC is staffed by the CLC Director and both of the clinical faculty. In the remaining two semesters, when the CLC is being used by internship students (who are required to gain most of their supervised experience at off-campus, community-based sites), the CLC Director augments coverage at the CLC with one of the two part-time clinical faculty (these two clinicians alternate semesters so they each work two of the three semesters per calendar year). In terms of student support staff, the CLC now has two student workers (as described above) who each work 12 hours per week at the CLC for minimum wage; and one Graduate Assistant (GA), assigned to support the CLC with 15 hours a week (the GA position also comes with partial tuition remission).

Technology. The initial design for viewing and recording student counseling sessions included ceiling mounted cameras and microphones in each of the four counseling rooms which were attached to VHS recorders and television sets in the viewing room. Over the years, several updates were made to this recording and viewing system (as was required due to changes in technology and failures in the recording processes). Within a few years, the VHS format became obsolete and the system was overhauled to rely on DVDs.

In 2013, when the new CLC Director was hired, the administration also supported a major modernization of the CLC facilities to include significant renovations and technology updates (see Appendix for details and photos). At this time, the overall space in the CLC was redesigned to allocate six counseling rooms in what had previously been used for four counseling rooms. Additionally, the back hallway space was also equipped for session viewing and recording to allow it to be used for group counseling sessions, if needed. Space was taken from the large waiting area to create a new, smaller receptionist area. The previous receptionist area (which had been larger than actually needed) was redesigned to be used as a student-counselor work space and outfitted with five new computer works stations so students could work on client notes and files on site.

Considerable effort has been made to continually upgrade the technology used at the CLC to ensure students are gaining technological competencies as is expected in the counselor education field and will be expected of them in the counseling field (Jencius, Poynton, \& Patrick, 2007). During the renovations and 
enhancements made to the CLC in 2013, all of the session taping and recording equipment was upgraded to digital format. This included digital recording equipment for seven counseling spaces as well as six digital viewing stations in the supervision and viewing room (the seventh space, the group room, is only used when the back two counseling rooms are not in use, thus no more than six sessions can take place at one time). In addition to the purchase of all new recording and viewing equipment, upgrading digital required complete rewiring of the CLC facility. Finally, two large-screen televisions were added (one to the CLC Director's office, and one in the viewing room). These two additional viewing stations allow faculty supervisors to view all seven session rooms at the same time (with our new NICE system (see NICE, n.d., for additional detail)), or to focus on one session and play this session to provide live supervision lessons with students in the viewing room (or in the Director's office).

In order to comply with advances in the profession and new recommendations regarding EHR (electronic health records), a new digital recordkeeping and client scheduling program was purchased for the CLC in 2013 (see Titanium, n.d.). This upgrade required a substantial budget allotment as well as on-going financial support for yearly maintenance fees; however, the faculty felt this has been balanced by the ability to adequately prepare students for similar technology they will face in off-campus internship sites and later in employment (Jencius et al., 2007). As part of this technological upgrade, a client input-station was added next to the receptionist center-So new clients can enter their own intake data into the system. Student counselors can pull this data up on a tablet computer which they can take into the intake with them. This digitalization of the records and processes at the CLC has helped reduce the risk of accidental breeches by limiting paper records.

Safety. As times have changed, so has the need to upgrade safety features in the CLC. Due to the increased need for safety planning across all universities, the CLC now undergoes a yearly safety inspection to ensure the facility maintains readiness for the variety of potential crises and emergencies that could arise there at any time. CLC faculty and staff are now trained regarding safety issues specific to the CLC every fall. Over the last two years, several new CLC procedures were implemented to increase the safety of CLC operations: All new practicum students now undergo a mandatory safety training before beginning any clinical work at the CLC (in addition to clinic orientation and mandatory privacy/record management training); the back door of the clinic now remains locked at all times and all students and staff are required to enter the facility from the main front door (where clients enter); and the viewing room door now remains locked during all times when clients are in the CLC.

Additionally, in the last two years, several safety features were added to the CLC to include: new and brighter lighting in the central hallways; an upgraded alarm for the building; two panic buttons for student and staff use; additional mobile panic buttons (that can be taken into session rooms with student counselors if desired); an internal phone system (with two-way phones in each counseling room connected each room to the viewing/supervision room); a camera in the waiting room so that faculty and campus security can view this area if needed; and an identification card lock has been added to the viewing room door, requiring students and staff must slide their identification cards to enter.

Clients. Initially when the CLC opened, the clients served were mostly referrals from the local churches, overflow for county mental health services, and local probation services (basically individuals, couples, and families who had no other options or resources for counseling and mental health services). Now, as the reputation of the CLC has grown, more clients are self-referrals and referrals from private practitioners in the 
area. Overall, clients seen at the CLC include a wide variety of presenting issues such as: systemic family dysfunction, couple issues, parenting issues, developmental and adjustment issues, biogenic mental health disorders, mental health disorder, mental health disorder with co-morbid substance abuse, spiritual issues, and mandated court referrals. This varied list of presenting issues has provided student counselors with a plethora of training and professional development opportunities.

\section{Future Directions}

By necessity, the CLC is a flexible and dynamic facility. It continues to evolve as the needs of the counseling program it supports have varied (e.g., changes in the focus of the degrees), as the faculty has changed, and as client needs have changed. Currently, the CLC is undergoing a slight title revision and is in the process of pursuing institutional permission for a logo that will be separate and distinct from approved institutional logos. Whereas the CLC previously had been named the Community Life Center, the name has recently been changed to the Community Life Counseling Center (to emphasize that the facility provides counseling services). The acronym CLC will be retained as it has recognition in the community among referral agents. A tag line of "Outreach at UMHB" has also been proposed to emphasize that the CLC serves the community but not the UMHB student body.

\section{Summary}

As described, the CLC is a dynamic and flourishing counselor training facility which is constantly evolving to meet the changing training needs of the clientele it serves and the Graduate Counseling Program. The two most constant themes in the successful establishment and management of the CLC could easily be described as strong administrative support and faculty dedication. Without complete support from the university administration, the CLC would never have made it past the planning phase. Administrative support is considerably more complex than mere budget support (although clearly, adequate budgeting is essential). Opening the CLC required long-term vision and considerable administrative commitment to fully understand the potential value that this type of training facility could bring to the counselor education program and how this benefit would outweigh the potential risks (e.g., legal liability and added operational costs). However, administrative support alone cannot guarantee the success of a training facility like the CLC. This type of training facility takes considerable faculty dedication, time, and effort to be successful. Faculty must have a strong interest not only in training students, but in clinical work as well. It takes a consistent team effort to provide faculty coverage and supervision to operate a fully-functioning mental health clinic manned by student-counselors and to address the challenges that emerge (not only client situations but also questions about student competency). Finally, faculty must seek continuous improvement to ensure the facility and training being offered to students continue to mirror the growth and technological advances in the counseling profession.

\section{References}

American Counseling Association. (2011). 2011 Statistics on mental health professions. Alexandria, V.A.: Author. Retrieved from http://www.counseling.org/knowledge-center/licenure-requirements

American Counseling Association. (2014). 2014 code of ethics. Alexandria, V.A.: Author. Retrieved from http://www.counseling.org/knowledge-center/ethics

City-data.com. (2014). Retrieved from http://www.city-data.com/city/Belton-Texas.html

Council for Accreditation of Counseling and Related Educational Programs. (2009). Section III: Professional practice (pp. 14-16) in 2009 standards. Retrieved from http://www.cacrep.org/ 
Council for Accreditation of Counseling and Related Educational Programs. (2013). CACREP annual report. Retrieved from http://www.cacrep.org/about-cacrep/publications/

Council for Accreditation of Counseling and Related Educational Programs. (n.d.). Directory of accredited programs. Retrieved from http://www.cacrep.org/directory/

Department of Defense, Office of the Secretary. (2014, July 17). TRICARE certified mental health counselors final rule. Federal Register, 79(137), 41636-41642. Retrieved from http://www.gpo.gov/fdsys/pkg/FR-2014-07-17/pdf/2014-16702.pdf

Engels, D. E., Barrio Minton, C. A., Ray, D. C., \& Associates. (2010). The professional counselor: Portfolio, competencies, performance guidelines, and assessment (4th ed.). Alexandria, V.A.: American Counseling Association.

Graduate Counseling Program Requirements. (2014). In 2014-2015 UMHB graduate catalog (p. 37). Retrieved from http://registrar.umhb.edu/catalog

Gutheil, T. G., \& Gabbard, G. O. (1993). The concept of boundaries in clinical practice: Theoretical and risk-management dimensions. American Journal of Psychiatry, 150, 188-196.

Henderson, P. (2010). The new handbook of administrative supervision in counseling (Rev. ed.). N.Y.: Rutledge.

Jencius, M., Poynton, T., \& Patrick, P. (2007). Technical competencies for counselor education: Recommended guidelines for program development. Retrieved from files.acesonline.net/doc/2007_aces_technology_competencies.pdf

Mobley, A. K., \& Myers, J. E. (2010). Developing and maintaining counselor education laboratories (2nd ed.). Alexandria, V.A.: Association for counselor education and supervision. Retrieved from http://www.acesonline.net/wp-content/uploads/2011/08/mobley_myers.pdf

Myers, J. E., \& Smith, A. W. (1995). A national survey of on-campus training in counselor education. Counselor Education and Supervision, 35, 70-81.

National Board for Certified Counselors. (2012). National Board for Certified Counselors (NBCC) Code of Ethics. Greensboro, N.C.: Author. Retrieved from http://www.nbcc.org/

NICE (n.d.). Retrieved from http://www.nice.com/

Our history. (n.d.). Retrieved from http://about.umhb.edu/our-history

Texas State Board of Professional Counselors. (2014). Apply for a new license-requirements (paragraph 6). Retrieved from https://www.dshs.state.tx.us/counselor/lpc_appy.shtm

Titanium. (n.d.). Retrieved from http://www.titaniumschedule.com 